\title{
IDADE RADIOMÉTRICA DO GRANITO DE CAMPO FORMOSO, BA - UMA IDADE MÍNIMA PARA O GRUPO JACOBINA
}

\author{
JOAQUIM RAUL TORQUATO*, MARIA ALBA FARIAS TANNER \\ DE OLIVEIRA* e RICHARD LESTER BARTELS*
}

\begin{abstract}
The Campo Formoso granite represents the magmatic phase of the remobilized Pre-Jacobina basement, located within an arc defined by the Serra de Jacobina, north of Campo Formoso, Bahia. Intrusive relationships between this granite and the Jacobina Group metasediments, gradational changes in textures and compositions between the granite and basement rocks, and the general structural-topographic expression of this arc suggest a mantled gneiss dome model for this area.

This work establishes a $\mathrm{Rb} / \mathrm{Sr}$ whole rock isochron age of $1911 \pm 13 \mathrm{~m}$.y. for the Campo Formoso granite,

This date is interpreted as the age of the development of the structure, as well as a minimun age for the Jacobina Group metasediments.

$\mathrm{K} / \mathrm{Ar}$ dates on muscovites from the Campo Formoso granite are concordant with the $\mathrm{Rb} / \mathrm{Sr}$ isochron. It is suggested that a lower regional thermal gradient in the Campo Formoso area during Transamazonic time is the cause for a more rapid cooling environment.
\end{abstract}

INTRODUÇÃo Ā noroeste da Serra de Jacobina, na região de Campo Formoso, ocorre um corpo granítico, ao qual Brito Neves (1972) deu o nome de Granito de Campo Formoso e considerou-o como sendo de origem metassomática com refusão local. Tanner de Oliveira et al. (1974) descrevem-no como sendo magmático, intrusivo no Grupo Jacobina, com material formado por anatexia a partir dos gnaisses encaixantes pertencentes ao embasamento regional.

Com o presente trabalho, procuramos obter não só a sua idade, mas atendendo a que ele é intrusivo no Grupo Jacobina, uma idade mínima para aquele grupo.

GEOLOGIA REGIONAL A região de Campo Formoso está situada no contato entre duas grandes unidades litoestratigráficas: o grupo Jacobina e o Granito de Campo Formoso.

O Grupo Jacobina foi inicialmente descrito por Branner (1910) como um conjunto de quatro blocos independentes e separados por falhas. Daí para cá, muitos têm sido os autores que se dedicaram ao seu estudo, sendo de salientar Kegel (1959 e 1963) que teceu considerações sobre a sua origem e estrutura, Leo et al. (1964) que definiram a sua estratigrafia básica, mais tarde modificada por Griffon (1964, 1967), Mascarenhas (1969) e Jordan (1972). A unidade ocupa uma estreita faixa de terreno, com larguras médias inferiores a 10 quilômetros e extensão da ordem dos 180 quilômetros, de direção geral N-S com forte encurvamento em forma de arco, na região de Senhor do Bonfim, provocado pela intrusão do corpo granítico objeto do presente trabalho, o qual provavelmente representará um domo gnaíssico do manto, remobilizado do embasamento.

\footnotetext{
* Instituto de Geociências - Projeto Geoquímica - UFBa.
} 
Recentemente, Jardim de Sá et al. (1976), Sims (1976) e Mascarenhas (1976), durante o XXIX Congresso Brasileiro de Geologia, definiram melhor os conceitos de çorrelação com outras unidades, evolução e origem do referido Grupo. Como um todo, o Grupo (Leo et al., 1964) pode ser dividido em quatro Formaçōes: Cruz das Almas (xistos e quartzitos intercalados); Rio do Ouro (quartzitos verdes e brancos) e Serra do Córrego (quartzitos e metaconglomerados auríferos). Atualmente a Formação Bananeiras é incluída na Formação Gruz das Almas.

$\mathrm{Na}$ região da Mina de Pedrinhas, através de um programa de sondagens da PROGEO, foi verificada a existência de uma descontinuidade angular entre os corpos ultrabásicos da base da Serra de Jacobina e os quartzitos suprajacentes.

O Granito de Campo Formoso, compreende aproximadamente 1.000 quilômetros quadrados. Seus contatos a norte e sul são com migmatitos e gnaisses, a oeste encontra-se parcialmente coberto por calcários do Grupo Bambuí e a este o contato se faz com os metassedimentos epizonais do Grupo Jacobina.

O contato com o Grupo Jacobina é nítido como sendo de origem magmática e o granito apresenta, por vezes, xenólitos de quartzito verde e apófises cortando os metassedimentos (Tanner de Oliveira et al., 1974).

A sua implantação foi o resultado de anatexia a partir dos granitos e gnaisses regionais, sob condições de alta pressão de água que permitiu a cristalização da moscovita. A ausência quase total de minerais acessórios foi possivelmente uma conseqüência química-mineralógica das rochas primitivas.

Petrograficamente, apesar de serem bastante homogêneas, as rochas do corpo granítico se distribuem entre granodioritos, quartzo monzonitos e granitos (Tanner de Oliveira, op. cit.).

Numerosas falhas e fraturas transversais à Serra afetam tanto o granito de Campo Formoso, como as rochas do Grupo Jacobina.

RESULTADO E DISCUSSÃo A localização das amostras está dada na Fig. 1 e os resultados analíticos, obtidos por análise radiométrica $\mathrm{Rb} / \mathrm{Sr}$ e $\mathrm{K} / \mathrm{Ar}$ nas

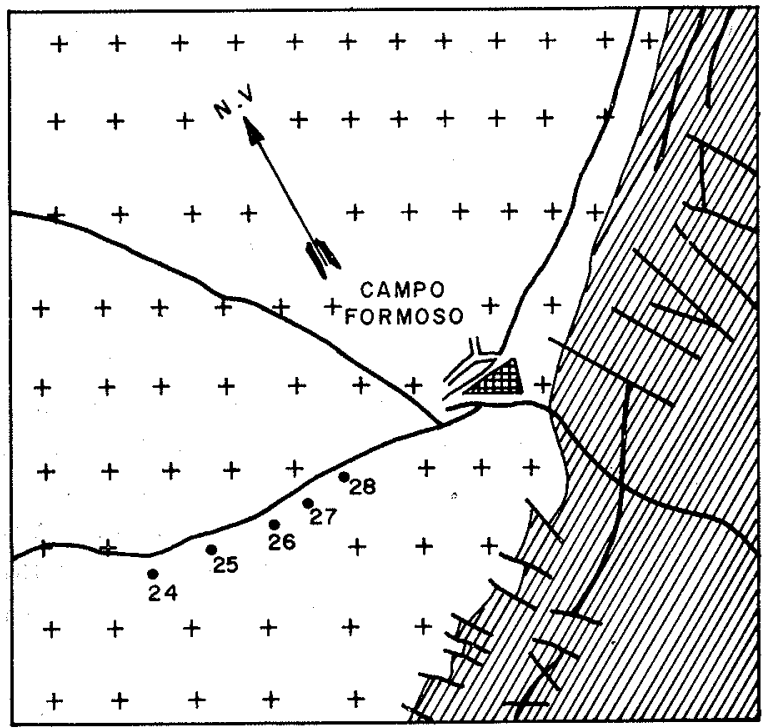

Convencöes

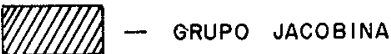

$+t+$ - GRANITO DE CAMPO FORMOSO

- $\quad$ - amostra - t b

- FALHAS

- - ESTRADADAS

Figura 1 - Localização dos pontos de amostragem

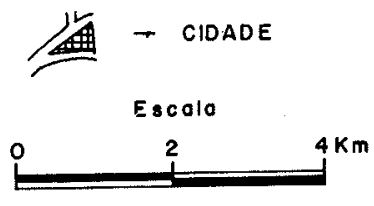


. I e II e na Fig. 2. A sua descrição petrogrâfica está dada em apêndice.

Tabela I

\begin{tabular}{|c|c|c|c|c|c|c|}
\hline $\mathbf{R}$ & No CAMPO & $\begin{array}{c}\text { Rb } \\
\text { ppm }\end{array}$ & $\begin{array}{c}\text { Sr } \\
\text { ppm }\end{array}$ & $\begin{array}{ll}87 / 86 \\
\mathrm{Sr} / & \mathrm{Sr}\end{array}$ & $\begin{array}{l}87 / 86 \\
\mathrm{Rb} / \mathrm{Sr}\end{array}$ & $\begin{array}{c}\text { Idade } \\
\text { convencional } \\
\text { m.a. }\end{array}$ \\
\hline 76 & TB -24 & 246 & 98 & 0,918 & 7,42 & $1926 \pm 51$ \\
\hline 36 & TB -25 & 248 & 121 & 0,877 & 6,03 & $1909 \pm 46$ \\
\hline 87 & TB -26 & 266 & 139 & 0,869 & 5,63 & $1958 \pm 52$ \\
\hline 88 & TB -27 & 393 & 125 & 0,975 & 9,34 & $1935 \pm 43$ \\
\hline 89 & TB -28 & 445 & 79 & 1,198 & 17,10 & $1933 \pm 42$ \\
\hline 90 & $\mathrm{CM}-32 / 40$ & 82 & 175 & 0,747 & 1,36 & $2049 \pm 126$ \\
\hline
\end{tabular}

Todas as determinações foram efetuadas em rocha total

A idade convencional foi calculada usando-se:

$$
\begin{gathered}
\lambda \mathrm{Rb}=1,47 \times 10^{-11} \text { anos }^{-1} \\
\left(87_{\mathrm{Sr}} / 86_{\mathrm{Sr}}\right) \mathrm{i}=0,705 \pm 0,002
\end{gathered}
$$

As razões $\left(87_{\mathrm{Sr}} / 86_{\mathrm{Sr}}\right)$ foram normalizadas para $\left(8_{\mathrm{Sr}} / 86_{\mathrm{Sr}}\right) \mathrm{n}=0,1194$

Os valores de $\mathrm{Rb}$ e $\mathrm{Sr}$ foram determinados através de fluorescência de raios $\mathrm{X}$

Idade isocrônica com $\left(87_{\mathrm{Sr}} / 86_{\mathrm{Sr}}\right) \mathrm{i}=0,708 \pm 0,001$ igual a $1911 \pm 13$.

Tabela II

\begin{tabular}{c|c|c|c|c|c|c}
\hline SPK & No CAMPO & MATERIAL & $\% \mathrm{~K}$ & $\begin{array}{c}40 \text { Ar rad. } \\
\text { ccSTP/gX10-4 }\end{array}$ & $\begin{array}{c}40 \text { Ar. Atm. } \\
\%\end{array}$ & $\begin{array}{c}\text { Idade } \\
\text { m.a. }\end{array}$ \\
\hline 3618 & TB - 24 & Moscovita & 8,9 & 10,95 & 0,9 & $1831 \pm 72$ \\
$993^{*}$ & Ba-66-PB-99 & Moscovita & 8,85 & 12,82 & 3,4 & $2027 \pm 157$ \\
\hline
\end{tabular}

' Determinação efetuada por F. J. Táyora (1969), incluída em Cordani et al. (1969). Os dados analíticos referentes ao $\mathrm{Ar}^{40}$ radiogênico e à idade aparente são diferentes dos publicados anteriormente, em virtude de erro de cálculo verificado recentemente, segundo comunicação escrita de U. G. Cordani (1977)

Os dados analíticos foram obtidos no Centro de Pesquisas Geocronológicas da Universidade de São Paulo. Para as análises $\mathrm{Rb} / \mathrm{Sr}$ foi usado o tratamento químico preconizado por Allsopp et al. (1968), modificado de acordo com as normas de trabalho deste laboratório. A obtenção das razões isotópicas teve lugar num aparelho marca Variant-Mat modelo TH-5, usando filamento duplo de rênio com $6 \mathrm{kV}$ de voltagem de aceleração. A determinação da composição isotópica e a precisão do método estão amplamente descritos em Torquato (1974). Com este espectrômetro obteve-se, como média de 36 determinações do $\mathrm{Sr}$ normal $\left(\mathrm{SrCO}_{3}\right.$ Eimer \& Amend), o valor de 0,7082 $\pm 0,0003$. 


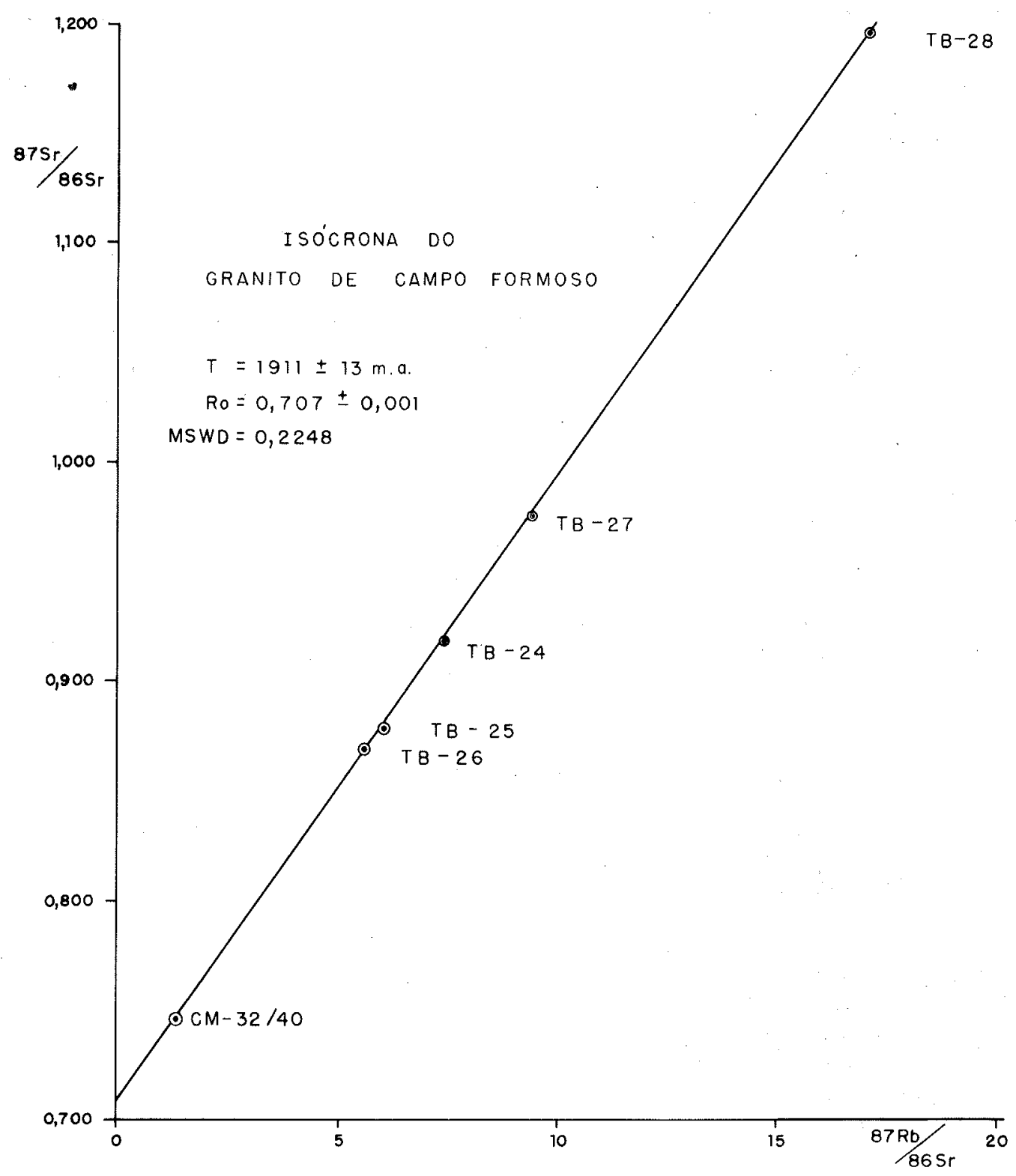

Figura 2 - Isócrona do granito de Campo Formoso

Para as determinações $\mathrm{K} / \mathrm{Ar}$ foram usadas as técnicas descritas por Amaral et al. (1966).

Os cálculos foram efetuados no Centro đe Computação Eletrônica da Universidade de São Paulo, usando-se os programas do C.P.Geo. identificados como PRBSR, PISODY e PARGON. 
Além da amostra BA-66-PB-99, anteriormente analisada por Tavora, cujos dados encontram-se em Cordani et al. (1969), foram datadas seis amostras, cinco colhidas nos arredores de Campo Formoso e uma (CM-32/40) fornecida pela firma PROGEO e pertencente a um testemunho de sondagem da mina de cromo de Pedrinhas.

Conforme se pode verificar pela análise das Tabs. I e II, existe concordância, dentro do erro experimental, entre as análises efetuadas pelo método $\mathrm{Rb} / \mathrm{Sr}$ e as determinaçōes $\mathrm{K} / \mathrm{Ar}$.

De salientar o bom alinhamento dos pontos na linha isocrônica e a homogeneidade das amostras, uma vez que o parâmetro estatístico MSWD (média da soma ponderada dos quadrados dos desvios da média) foi igual a 0,2248.

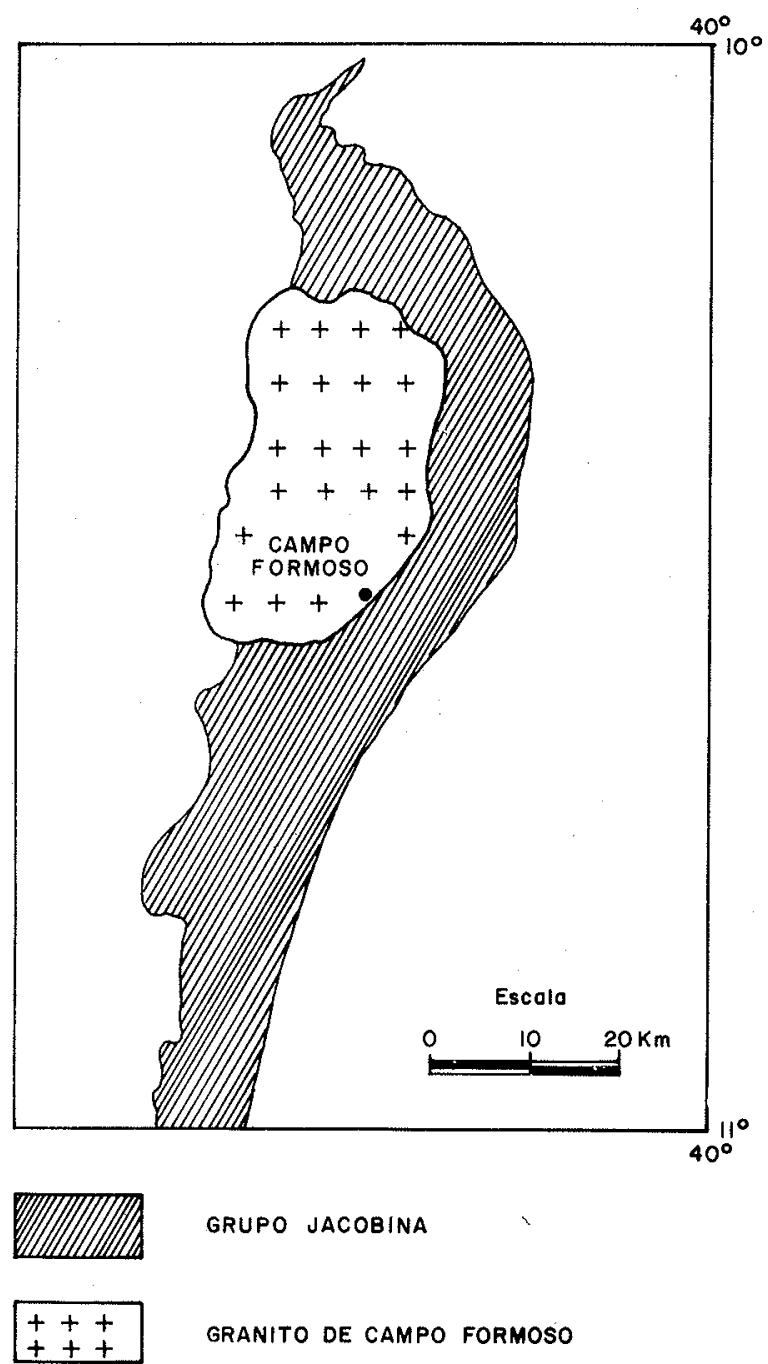

Figura 3 - Relação geológica entre o granito de Campo Formoso e as rochas do Grupo Jacobina 
Foi tentada outra isócrona levando em conta apenas os valores das amostras colhidas em superfície, nos arredores de Campo Formoso. Os valores obtidos (Ro = $=0,705 \pm 0,003 ; \mathrm{T}=1933 \pm 27$ e MSWD $=0,2289$ ) confirmaram não haver diferença sensivel entre estas amostras e aquela obtida em testemunho de sondagem.

Um caso interessante e digno de nota é a idade concordante $\mathrm{Rb} / \mathrm{Sr}$ e $\mathrm{K} / \mathrm{Ar}$. Como ficou descrito anteriormente, o granito de Campo Formoso é intrusivo nos metassedimentos do Grupo Jacobina e, através de datações $\mathrm{K} / \mathrm{Ar}$ contidas e discutidas nos trabalhos de Cordani et al. (1969), Cordani (1973) e Jardim de Sá et $a l$. (1976), verifica-see que toda essa região foi afetada pelo Ciclo Trans-Amazônico com idades obtidas em biotitas e rochas totais ao redor de 1800 milhões de anos. Sabendo-se que as temperaturas de retenção de argônio são quase as mesmas para as moscovitas e biotitas, seria de esperar que a idade da amostra $\mathrm{Tb}-24$ fosse fornecer um padrão semelhante. $O$ fato de, pelo contrário, a idade $K / A r$ ser semelhante à idade $\mathrm{Rb} / \mathrm{Sr}$, mostra-nos que a região de Campo Formoso, naquele tempo, já se encontrava bastante fria, permitindo o rápido esfriamento do corpo granítico.

Caminhando para sul, entre Tanquinhos e Salvador, vamos encontrar idades $\mathrm{K} / \mathrm{Ar}$ e $\mathrm{Rb} / \mathrm{Sr}$ mais jovens, ao redor de $1700 \mathrm{~m}$.a., este fato nos leva a admitir que o Ciclo Trans-Amazônico ao longo da região costeira, teve um comportamento diferente a norte e a sul pois que, enquanto na região de Campo Formoso já tinha baixado a temperatura regional para o nível de retenção de argônio pelas moscovitas, nas regiōes mais meridionais (entre Tanquinhos e Salvador), ainda se mantinha quente, até mesmo com fenômenos magmáticos, Bartels et al. (em preparação).

A datação do Granito de Campo Formoso, serviu ainda para poder determinar uma idade mínima para as rochas do Grupo Jacobina. Cordani et al. (1969) admite que as rochas epimetamórficas do Grupo Jacobina se formaram provavelmente durante o Ciclo Trans-Amazônico; Cordani (1973) reafirma tal conclusão e Jardim de Sá et al. (1976) ao tratar do desenvolvimento do Craton de São Francisco durante o proterozóico, encampa as mesmas idéias.

Com a datação do Granito de Campo Formoso, uma vez que ele ê intrusivo no Grupo Jacobino (Tanner de Oliveira et al., 1974 e figura 3), temos agora uma idade mínima de boa confiabilidade para o referido Grupo $-1911 \pm 13$ m.a..

\section{CONCLUSÕES}

1 - A idade do Granito de Campo Formoso é $1911 \pm 13$ milhões de anos.

2 - O resfriamento dô corpo granítico foi rápido, uma vez que; dentro do erro experimental, as idades $\mathrm{K} / \mathrm{Ar}$ e $\mathrm{Rb} / \mathrm{Sr}$ são concordantes.

3 - Como o granito é intrusivo nos metassedimentos do Grupo Jacobina, a idade mínima daquele grupo é a do Granito de Campo Formoso.

4 - Os efeitos do Ciclo Trans-Amazônico foram diferentes na região de Campo Formoso e entre Tanquinhos e Salvador pois, apesar de ter afetado toda a área, o esfriamento e a calma tectônica se deu de norte para sul. 
Agradecimentos Os autores agradecem ao Professor Doutor Umberto G. Cordani, Diretor do Centro de Pesquisas Geocronológicas da Universidade de São Paulo, as facilidades concedidas para a datação das amostras.

Igửalmente agradecimentos são devidos à Companhia de Mineração PROGEO pela cessão de uma amostra de testemunho de sondagem.

Por último, agradecemos à Professora Adelaide Mussi Santos, executora do Convênio FNDCT-221-CT pelo apoio financeiro, sem o qual não poderia ter sido realizado o presente trabalho.

\section{BIBLIOGRAFIA}

ALLSOPP, H. L., ULRYCH, T. J. e NICOLAYSEN, L. O. - 1968 - Dating some significant events in the history of the Swaziland System by the $\mathrm{Rb}-\mathrm{Sr}$ isochron methods. Canadian Journal of Earth Sciences, 5:605

AMARAL, G., CORDANI, U. G., KAWASHITA, K. e REYNOLDS, J. H. - 1966 Potassium argon ages of basaltic rocks from Southern Brazil. Geochim. Cosmochim. Acta 30 (2) : $159-189$

BARTELS, R. L., TORQUATO, J. R. e TANNER DE OLIVEIRA, M.A.F. - Em preparação - A geochronological investigation in granulite terrain northeast of Feira de Santana, Bahia State.

BRANNER, J. C. - 1910 - The geology and topography of Serra de Jacobina, State of Bahia, Brazil. Amer. Jour. Sci., New Haven, Série 4, 30 (178) : 285 - 392.

BRITO NEVES, B. B. de - 1972 - Inventário hidrogeológico do Nordeste. Folha 24, Aracajú - SO Recife - SUDENE.

CORDANI, U. G. - 1973 - Evolução geológica pré-cambriana da faixa costeira do Brasil, entre Salvador e Vitória. Tese de Livre Docência - Univ. São Paulo. 98 pp.

CORDANI, U. G., ISOTTA, C. A. L. e ABREU, A. C. S. - 1969 - Reconhécimento geocronológico do embasamento da região oriental do Estado da Bahia. Anais XXIII Congr. Bras. Geol., Salvador, pp. 159- 165.

GRIFFON, J. C. - 1964 - Dados estratigráficos e estruturais da Serra de Jạcobina entre Jacobina e Pindobaçu (NW da Bahia). Salvador, Escola de Geologia da UFBa, Relatório inédito para a SUDENE

GRIFFON, J. C. - 1967 - Apresentação do mapa geológico (1:100.000) da parte central da Serra de Jacobina - Bahia. Anais XXI Congr. Bras. Geol., Curitiba. Resu mo das Comunicações. Bol. Paranaense de Geol. 76 : 33 - 34

JARDIM DE SÄ, E. F., McREATH, I., BRITO NEVES, B. B. de e BARTELS, R. L. - 1976 - Novos dados geocronológicos sobre o cráton de São Francisco no Estado da Bahia. XXIX Congr. Bras. Geol. - Belo Horizonte (em impressão).

JORDAN, H. - 1972 - Die Minas - Gruppe in Nordest - Bahia, Brasilien. Geol. Rundschau, 61 (2) : 441 - 469

KEGEL, W. - 1959 - Estudos geológicos na zona central da Bahia Rio de Janeiro. DNPM/DGM, Bol. 198, $35 \mathrm{pp}$.

KEGEL, W. - 1963 - A estrutura geológica da Serra de Jacobina (Bahia). DNPM/DGM, Bol. 207, 21 pp.

LEO, G. W., COX, D. P. e CARVAlho, J. P. P. - 1964 - Geologia da parte sul da Serra de Jacobina, Bahia, Brasil. DNPM/DGM, 209. 87 pp.

MASCARENHAS, J. de F: - 1969 - Mapeamento geológico da parte norte da Serra de Jacobina - Ba. Bol. Soc. Bras. Geol., 18 (1) : 1 - 22.

MASCARENHAS, J. de F. - 1976 - Estruturas do tipo "greenstone belt" no leste da Bahia. XXIX Congr. Bras. Geol. Belo Horizonte (em impressão). 
SIMS, J. F. M. - 1976 - A geologia da série aurífera de Jacobina, nas vizinhanças de Jacobina, Bahia, Simpósio sobre ouro, Ouro Preto, inédito.

TANNER DE OLIVEIRA, M. A. F., FRÓES, R. J. B. e TANNER DE OLIVEIRA, T. - 1974 - Granito de Campo Formoso - Ba. Anais XXVIII Congr. Bras. Geol. Porto Alegre 5 : $125-132$.

TORQUATO, J. R. - 1974 - Geologia do sudoeste de Moçamedes e suas relações com a evolução tectônica de Angola. Tese de Doutoramento. Univ. São Paulo. 243 pp.

\section{APÊNDICE}

Descrição petrográfica sumária das amostras analisadas

Amostra TB - 24 - GRANITO

A rocha tem cor rósea, granulação fanerítica média, textura alotriomórfica tendendo a hipidiomórfica.

Mineralogia: Quartzo é anédrico intersticial fraturado com extinção ondulante; os feldspatos são microclina anédrica, poiquilítica incluindo biotita e oligoclásio subédrico, por vezes mirmequitizado; ambos os feldspatos alteram-se de forma incipiente em sericita e argilo-minerais.

Amostra TB - 25 - QUARTZO - MONZONITO

As características texturais são as mesmas da amostra 24; turado.

Mineralogia: Quartzo é anédrico intersticial, extinção ondulante pouco fra-

Os feldspatos encontram-se bastante alterados em sericita e argilo-minerais biotita em clorita (peninina).

O oligoclásio excede a microclina, o mesmo ocorre com a biotita em relação a moscovita.

Amostra TB - 26 - QUARTZO - MONZONITO

A rocha tem cor cinza claro, granulação fanerítica média, textura hipidiomórfica.

Mineralogia: Quartzo anédrico intersticial, extinção fracamente ondulante; oligoclásio ocorre em maior proporção que nas amostras anteriores, tem forma subédrica, alguns grãos são zonados com núcleo mais cálcico que a periferia.

Moscovita subédrica a anédrica intersticial excede a biotita.

Amostra TB - 27 - GRANITO

A rocha tem cor rósea, granulação fanerítica média textura alotriomórfica.

Mineralogia: Quartzo é anédrico intersticial, apresentando aspectos de refusão com contato reentrante.

Os feldspatos são oligoclásio e microclina, aquele ocorre em quantidade menor que esta; a microclina apresenta variação granulométrica de fanerítica fina a média, é poiquilítica incluindo biotita; moscovita ocorre em pequena quantidade. 


\section{Amostra TB - 28 - GRANITO}

A rocha tem coloração rósea com tons acinzentados, granulação fanerítica média*e textura alotriomórfica; observou-se texturas de esforço posterior à cristalização.

Mineralogia: Quartzo e muscovita são anédricos intersticiais; microclina quando ocorre em grãos maiores são anédricos, entretanto alguns grãos de menor tamanho são subédricos.

Aqui o oligoclásio é mais sódico, tem os planos de geminação encurvados, , mesmo ocorrendo com a biotita e moscovita.

\section{Amostra CM - 32/40 - GRANODIORITO}

A rocha tem coloração cinza, granulação fanerítica média e textura hipidio'nórfica.

Mineralogia: Quartzo, microclina e muscovita são anédricos intersticiais, embora haja moscovita de alteração dos feldspatos.

Oligoclásio é subédrico e quantitativamente excede a microclina.

Observou-se rara biotita. 